\title{
Experiences and Countermeasures of a Perinatal Ward Nursing Manager Dealing with Family Members' Problematic Behaviors
}

\author{
Rie Wakimizu1, Yumiko Saito², Makoto Saito ${ }^{3}$ \\ ${ }^{1}$ Department of Child Health Care Nursing, Division of Health Innovation and Nursing, Faculty of Medicine, University of \\ Tsukuba, Ibaraki, Japan \\ ${ }^{2}$ Doctoral Program in Nursing Science, Graduate School of Comprehensive Human Sciences, University of Tsukuba, Ibaraki, Japan \\ ${ }^{3}$ Department of Child Health, Faculty of Medicine, University of Tsukuba, Ibaraki, Japan \\ Email: riewaki@md.tsukuba.ac.jp
}

How to cite this paper: Wakimizu, R., Saito, Y. and Saito, M. (2021) Experiences and Countermeasures of a Perinatal Ward Nursing Manager Dealing with Family Members' Problematic Behaviors. Open Journal of Nursing, 11, 981-1001.

https://doi.org/10.4236/ojn.2021.1111079

Received: October 21, 2021

Accepted: November 26, 2021

Published: November 29, 2021

Copyright (c) 2021 by author(s) and Scientific Research Publishing Inc. This work is licensed under the Creative Commons Attribution International License (CC BY 4.0).

http://creativecommons.org/licenses/by/4.0/

\section{Open Access}

\begin{abstract}
Background: When family members and/or patients behave in a problematic way, this hinders the provision of safe and secure medical care. During the perinatal period, a family's relationships and functions change significantly, and each family member is prone to experiencing stress. As such, conflict arises easily between family members and medical staff. Aims: Therefore, we conducted this study to shed light on the following phenomena: 1) family members' problematic behaviors; 2) the concerns of a perinatal ward nurse manager (hereafter referred to as the manager) and ward nurses; and 3) countermeasures carried out by the manager, together with the ward nurses, based on the manager's experiences. Methods: We conducted an 80-minute, semi-structured interview with the manager, following which we analyzed the content of her narrated accounts. Results: According to the findings, 1) family members' problematic actions include verbal abuse; arrogance, unreasonableness, and selfish behaviors; and violent conduct; 2) the manager's and ward nurses' fears and worries about family members' problematic behaviors; responses to gradually becoming involved with family members; and resistance to staying involved with family members following patient discharge. In addition, we examined 3) countermeasures carried out by the manager together with the ward nurses: resolute and consistent responses to family members' problematic behaviors; attempted enforcement measures taken to deal with family members who exhibit problematic behaviors; engagement while trying to avoid conflict with family members; preparation that anticipates the occurrence of problematic conduct; cooperation with the medical team; cooperation with the hospital organization; cooperation with social resources outside the hospital; and patient protection. Conclusions: With
\end{abstract}


awareness of cooperation with the medical team toward family members who engage in problematic actions, the medical staff members try to unify their response and share their feelings of hardship with each other.

\section{Keywords}

Perinatal Care, Nursing, Family, Violence, Countermeasures

\section{Introduction}

In-hospital violence such as verbal abuse, physical violence, and (sexual) harassment committed by patients and their families toward staff at medical treatment sites not only causes stress to medical staff, but also hinders the provision of safe and secure medical care [1]. In some cases, medical staff who have been subjected to in-hospital violence cannot obtain sufficient support and are forced to quit. In recent years, in-hospital violence has emerged in pediatric medical practice, and creating countermeasures is an urgent issue [2] [3]. The causes of problematic behavior of family members have been shown to include requests for compliance with facility rules, medical treatment that is not in accordance with the will of the patient/family, and anxiety of the patient/family [1] [4], and as a countermeasure, staff members are reported to have a firm attitude, consistent responses, listening, and careful explanations [1]. Within facilities, the establishment of a sharing system after the occurrence of damage and the creation of response manuals and guidelines are mentioned, but less than $10 \%$ of staff recognize the effectiveness of these measures, and the measures are not sufficient [1]. In a previous survey of university hospitals and general hospitals in Japan, $35 \%-56 \%$ of the staff had experienced violence or other victimization by patients within the past year [5] [6] [7], and about $10 \%$ in pediatric medical settings [1]. A survey of pediatric hospitals in China revealed that about $70 \%$ of the staff had experienced victimization, and $94 \%$ of them were victimized by family members [3]. During the perinatal period, a family's relationships, roles, and functions change significantly, and each member is prone to suffering stress. Hence, the family is also more prone to becoming involved in conflicts with medical professionals. In a survey of perinatal wards in Japan, it was reported that nearly $30 \%$ of nurses experienced situations that appeared to be violence/ harassment from patients and patients' families [8]. However, no research has described, in detail, what kinds of problematic behaviors medical staff actually encounter and respond to in the field of perinatal medical treatment. Compared to other medical staff, nurses have the most opportunities to interact with family members. Among them, the head ward nurse (who is also the nurse manager) has many chances to interact not only with nurses but also with doctors, medical clerks, social workers, and regional comprehensive support centers; the head ward nurse also plays a vital role in providing team medical care. 
For this study, we used a survey to clarify: 1) family members' problematic behaviors; 2) the perspectives and concerns of a head ward nurse (hereafter referred to as "the manager") in a perinatal ward, as well as the ward nurses; and 3) countermeasures carried out by the manager together with the ward nurses, based on the manager's experiences.

\section{Methods}

\subsection{Data Collection Method}

The research subject (hereafter referred to as "the subject") is the head nurse (i.e. manager) in the perinatal ward of a general hospital in the Kanto region of Japan. We gathered the data in March 2019 through a semi-structured interview using a face sheet and an interview guide. We noted the details related to the subject's background characteristics and years of clinical experience on the face sheet, as well as information on what she had experienced thus far as a manager in the perinatal ward in terms of: 1) family members' problematic behaviors; 2) her perspectives and concerns, as well as those of the ward nurses; and 3) countermeasures that she carried out together with the ward nurses, focusing on several episodes that had left a strong impression, which she recounted in a private room. We recorded the interview on an IC recorder with her consent.

\subsection{Analysis Method}

We performed content analysis, which Krippendorff [9] defines as a technique "for making replicable and valid inferences about the context in which 'contex' is embedded based on the data". The manager's perspectives and concerns incorporate complex clinical phenomena such as the situations of puerperal women, husbands, and children; the home environment; information sharing between ward nurses and other medical staff; and collaboration after discussions. We chose this method because we thought it necessary to replace the narrative context obtained in the interview with interpreted data.

\subsubsection{Temporary Code Creation}

We created a verbatim account from the interview data recorded on the IC recorder. While carefully reading the verbatim account and respecting the context of the subject's narrative, we marked experiences involving: 1) family members' problematic behaviors; 2) the perspectives and concerns of the manager and the ward nurses; and 3) countermeasures carried out by the manager together with the ward nurses. We extracted the context as it was. Using parentheses, we supplemented unnecessary conjunctions, exclamations, hidden subjects and objects, and words that refer to pronouns. We summarized the phrases extracted in this way, being careful not to lose the meaning, and considered 1 to indicate a temporary code. When multiple pieces of content emerged in a single phrase, we divided the content according to type and treated the pieces of content as multiple temporary codes. 


\subsubsection{Code Creation}

We collected similar and duplicate pieces of content from the temporary code; we then carefully turned these into a single statement to avoid losing any meaning. Afterward, we created the code name. Following that, we returned to using the temporary code to confirm whether the code name represented the content. If there was a discrepancy, we carefully read the recording unit, and reviewed and repeatedly defined the code name.

\subsubsection{Subcategory Creation}

After setting a code name, we classified the data based on the similarity of content, and increased the degree of abstraction to form subcategories. After establishing the subcategory names, we corroborated the similarity of codes that make up each subcategory. Then, we compared the code and recording unit to confirm whether the subcategory name represented the content.

\subsubsection{Category Creation}

We broke down the subcategories based on the similarity of their content, and gave them category names with a higher degree of abstraction. After forming the category names, we verified the similarity of the subcategories that comprise each category; if there were any discrepancies, we returned to the analysis stage and made corrections. Next, we compared the category names with the subcategories to determine if the category names represented the content. If there was any discrepancy, we re-examined the category names.

\subsubsection{Ensuring Stringency of Results}

We carefully went over the data in a seminar with graduate students based on the data handling in accordance with ethical considerations, and we held discussions after concluding that there were no distortions or biases in our interpretations, classifications, and expressions. Each stage of the data analysis was supervised by pediatric and family nurse specialists who have thorough knowledge of qualitative research. If there were any disagreements between our opinions and those of the specialists, we returned to the previous stage of analysis, selected data that better represented the context of the subject's narrative and that carried explanatory power, and repeated the process of confirming with the specialists. After we completed the analysis, the manager carried out a member check to establish whether we had properly perceived her narrative. We mailed her a post-analysis sheet containing the code, subcategories, and categories that reflected her narrative to request that she affirm its accuracy; we subsequently obtained a reply.

\subsection{Ethical Considerations}

We conducted this study after receiving approval from our university's medical ethics committee (approval \#1238). We obtained informed consent from the subject. Before she signed the consent form, we explained that her participation in the survey was voluntary, that she could withdraw her consent or discontinue 
her participation at any time without suffering disadvantages, and that she would not be identified by any interview data collected during the data analysis or the publication process.

\section{Results}

\subsection{Subject}

The subject is a nurse manager with 29 years of clinical experience at a regional hospital (with 18 years of work experience in obstetrics and pediatrics). Further, she is a qualified nurse and midwife and the head of the perinatal ward.

\subsection{The Experiences of the Perinatal Ward Nurse Manager}

We extracted data from the 80 -minute, semi-structured interview regarding: 1) family members' problematic behaviors; 2 ) the perspectives and concerns of the manager and the ward nurses; and 3) countermeasures carried out by the manager and the ward nurses.

\subsubsection{Family Members' Problematic Behaviors}

In terms of family members' problematic behaviors, we extracted 3 categories, 8 subcategories, and 17 codes for [verbal abuse], [arrogant, unreasonable, and selfish behaviors], and [violent conduct] (Table 1).

Table 1. Family members' problematic behaviors.

\begin{tabular}{|c|c|c|}
\hline Category & Subcategory & Code (the subject is one of the family members) \\
\hline \multirow{3}{*}{ Verbal abuse } & $\begin{array}{l}\text { Verbal abuse from one family } \\
\text { member toward another due to the } \\
\text { couple's original relationship }\end{array}$ & $\begin{array}{l}\text { The wife, who was confined in the hospital in a state of absolute rest, } \\
\text { was accused by her husband: "It's your fault that I am experiencing } \\
\text { this hardship". } \\
\text { The husband, who was prohibited from visiting his wife due to DV, } \\
\text { called her frequently, saying abusive things like, "You reported it, } \\
\text { didn't you? You bitch, I'll kill you". }\end{array}$ \\
\hline & $\begin{array}{l}\text { Verbal abuse from one family } \\
\text { member toward the medical staff due } \\
\text { to the couple's original relationship } \\
\text { and associated restrictions and } \\
\text { rejections }\end{array}$ & $\begin{array}{l}\text { In order to protect a hospitalized pregnant wife, a nurse stepped in } \\
\text { to mediate a situation whereby the husband was mouthing off to his } \\
\text { wife. The nurse was subjected to yakuza-like screams of "This has } \\
\text { nothing to do with you, bitch"! and "Don't you fucking dare enter } \\
\text { this room"! } \\
\text { The husband shouted at the nursing manager, who decided to prohibit } \\
\text { the husband from visiting due to DV. He yelled, "What right do you } \\
\text { have to [prohibit me from visiting my wife]"? and "I'll kill you when } \\
\text { you get out of the hospital"! both by phone and at the hospital } \\
\text { entrance. }\end{array}$ \\
\hline & $\begin{array}{l}\text { Verbal abuse toward the medical } \\
\text { staff from family members who } \\
\text { cannot accept the fact that the } \\
\text { newborn is sick }\end{array}$ & $\begin{array}{l}\text { The newborn's respiratory condition did not improve, and the father } \\
\text { gravely threatened the doctors and nurses who proposed postponing } \\
\text { the discharge period. He said, “This is different from what you } \\
\text { promised yesterday"! and "You shouldn't have told me such } \\
\text { irresponsible things"! }\end{array}$ \\
\hline
\end{tabular}




\section{Continued}

Arrogance toward the medical staff on the part of family members who are stressed due to unexpected warnings and explanations of medical conditions
In response to the doctor, who started talking about transporting the newborn to another hospital because the newborn's condition had worsened, the father swore at the doctor in a horrifying voice and said things like: "I don't understand"! and "You'd better take responsibility for this"!

A husband defiantly refuted verbal warnings from the ward administrator regarding the rules of the ward, saying things like, "You're so annoying", "How stupid", and "Such useless things"!

When the doctor in charge of the newborn ward was explaining the newborn's condition, the husband glared at him, and listened without acknowledgement or nodding, and threatened the doctor at the end.

The husband came to the nurses' station with impolite requests such as "I want to slice this cake and eat it; have you got a knife"? or "Don't you have a teacup"? When he was told that it would be difficult to accommodate his requests, he openly clicked his tongue at us.

The husband acted disrespectfully toward the doctors, nurses, janitors, and anyone else, regardless of profession, with an air of "I pay you anyway so it's just normal to make you do whatever I want". the part of family members who fail to consider the other parties involved and their surroundings

Mature adult behavior was not exhibited, no matter how many times we warned them, and they continued to do things without regard for other patients and visiting families, such as having many relatives intrude in the hospital room, talking loudly, and eating smelly food.

The husband insulted a female doctor and looked at her condescendingly, saying things like, "I want to hear from another [male] doctor, not you".

A husband and his wife, who had been hospitalized for childbirth Violent conduct from family shouted at each other in a hospital room due to a trivial argument; this members and patients or from family developed afterward into a quarrel where they threw things at each members toward patients, resulting other. from the stress of the couple's original relationship and hospitalization

The husband pulled the hair of his wife, who was quiet with her head bowed down. He then asked her, "Are you deaf”?

Violent behavior of family members Violent conduct who have reached their peak in terms of mental and physical fatigue

The husband, who was warned by the chief nurse to only visit during visiting hours, got angry and threw his mobile phone on the sofa in the hospital room, saying, "I'm tired and forced myself to come here after work, you know"!

The father was furious and aimed to take a strike at the doctor, who had given an explanation about transporting the newborn to another

Violent conduct by family members who cannot accept the fact that their newborn is sick hospital because of the baby's worsening condition.

The father got angry at the doctors and nurses who explained the need to postpone discharge because the newborn had not yet recovered from a respiratory condition. The father threw the baby's sibling, who was 2 years old, into the air.

${ }^{\star}$ Family member(s) = family member(s) who exhibit problematic behaviors. 
Verbal abuse. One husband accused his wife, who was in a state of absolute rest, that it was her fault he had to balance both work and family life by himself, and he psychologically cornered her. In another case, the wife had already been subjected to domestic violence (DV) by her husband. Although the manager and staff took measures to prohibit her husband from visiting, since he often subjected his wife to verbal abuse (even in the hospital room), the wife still received incoming calls from her husband on her mobile phone every few minutes even after the visitation prohibition, and she was frightened. The husband also swore at the manager, who told him about the visitation prohibition. In another case, the newborn's condition was not good, and when the doctor explained the need to have the baby transferred to a high-functioning hospital, the father, who could not accept the situation, verbally abused the doctor.

Arrogant, unreasonable, and selfish behaviors. Some family members acted arrogant toward everyone. Even if the manager strictly warned them to comply with the ward's rules, they expressed a defiant attitude and argued with her. The manager explained that during one incident, a family member who was feeling stressed out was impolite and glared at her and the doctor in charge of the newborn baby, and also tried to get close to the doctor in charge of the newborn baby when the doctor was explaining about the baby's health status. In one case that involved misguided allegations, the staff explained to a family member that the hospital ward could not provide particular services that the family member was insistently requesting. The family member said, "Why can you not provide services, when we are paying the hospitalization fee"? In another instance, a family member unreasonably requested that a male doctor give him the explanation instead of the female doctor who was present, and who was about to give details on the newborn's the condition.

Violent conduct. The manager also reported violent conduct, such as quarrels between hospitalized patients and their family members, abuse from family members toward the patient, menacing actions from family members toward nurses, and doctors getting hit or toddlers getting thrown due to family members being angry.

\subsubsection{The Perspectives and Concerns of the Manager and the Ward Nurses}

Regarding the perspectives and concerns of the manager and the ward nurses, we extracted 3 categories, 6 subcategories, and 16 codes for [fears and worries about family members' problematic behaviors], [reactions to becoming involved with family members], and [resistance to staying involved with family members] (Table 2).

Fears and worries about family members problematic behaviors. According to the manager, one husband's attitude often changed suddenly, and just when one thought he was showing a straightforward, positive reaction to the nurses' call, sometimes his attitude was completely different the next day. Therefore, the nurses feared he might exhibit problematic behavior and attack 
Table 2. The perceptions and concerns of the manager and the ward nurses.

\begin{tabular}{|c|c|c|}
\hline Category & Subcategory & Code (if there is no special mention of the subject, the manager) \\
\hline \multirow{3}{*}{$\begin{array}{c}\text { Fears and } \\
\text { worries about } \\
\text { family members' } \\
\text { problematic } \\
\text { behaviors }\end{array}$} & $\begin{array}{l}\text { Tension and fears that may trigger } \\
\text { family members' problematic } \\
\text { behaviors }\end{array}$ & $\begin{array}{l}\text { Since I knew about his use of abusive language and violent behavior, I } \\
\text { was nervous during our first meeting. } \\
\text { I was uncertain if I had responded correctly to the husband, and even } \\
\text { now, I am afraid that the husband's behavior may change and that he } \\
\text { may turn on me. } \\
\text { Especially at night when there are few staff at work and it is difficult to } \\
\text { get help from colleagues, the nurses have been very nervous not to } \\
\text { strike a nerve when dealing with sensitive family members. } \\
\text { I heard from the nurses that they hesitate in fear, even when they } \\
\text { simply have to tell family members that it is time to turn the } \\
\text { lights off. }\end{array}$ \\
\hline & $\begin{array}{l}\text { Fear of being attacked by family } \\
\text { members }\end{array}$ & $\begin{array}{l}\text { After the husband, who was prohibited from visiting his wife (due to } \\
\text { DV), made threatening phone calls to his wife in the ward, the nurses } \\
\text { feared being attacked. On their way home, they went in groups to the } \\
\text { parking lot, which was a short distance away. } \\
\text { The abusive language they heard from family members remained in } \\
\text { their minds for a long time, even after the patient was discharged from } \\
\text { the hospital. When I come to the outpatient department with a patient, } \\
\text { I continue to be anxious and afraid that I might be attacked when I } \\
\text { come up to the ward. }\end{array}$ \\
\hline & $\begin{array}{l}\text { A concern that family members' } \\
\text { problematic behaviors may adversely } \\
\text { affect the patient in question and } \\
\text { other patients as well }\end{array}$ & $\begin{array}{l}\text { Due to the original relationship between the couple, it was difficult for } \\
\text { the patient to completely escape the violence and to mind control by } \\
\text { the family members. } \\
\text { I thought that if they weren't separated from their family members, I } \\
\text { wouldn't be able to protect the hospitalized patients and babies. } \\
\text { I was worried that even the patients in the adjacent room might have } \\
\text { been able to hear all the abusive language of the family members and } \\
\text { that it made them feel unpleasant. }\end{array}$ \\
\hline $\begin{array}{l}\text { Reactions to } \\
\text { becoming } \\
\text { involved with } \\
\text { family members }\end{array}$ & $\begin{array}{l}\text { Reaction to the fact that some } \\
\text { two-way communication with family } \\
\text { members has become possible }\end{array}$ & $\begin{array}{l}\text { I was happy when we were able to gradually have a conversation with } \\
\text { the family member. } \\
\text { The husband responded differently depending on the person, but I was } \\
\text { relieved when he listened and stopped his selfish behavior when I, the } \\
\text { chief nurse, told him: "You shouldn't do that". }\end{array}$ \\
\hline $\begin{array}{l}\text { Resistance to } \\
\text { staying involved } \\
\text { with family } \\
\text { members }\end{array}$ & $\begin{array}{l}\text { An out-of-place feeling toward } \\
\text { building an unpleasant relationship } \\
\text { with family members }\end{array}$ & $\begin{array}{l}\text { I was afraid that a co-dependent human relationship would form } \\
\text { between us as I interacted with the family members. } \\
\text { Even if good communication with the family members seems to have } \\
\text { been maintained, I do not feel that a true relationship of trust has been } \\
\text { established between us. }\end{array}$ \\
\hline $\begin{array}{l}\text { following patient } \\
\text { discharge }\end{array}$ & $\begin{array}{l}\text { The feeling of not wanting to become } \\
\text { involved with family members }\end{array}$ & $\begin{array}{l}\text { Although we knew that guards and police would come in case of an } \\
\text { emergency, we didn't have a single sense that we were protected at all } \\
\text { on a daily basis. }\end{array}$ \\
\hline
\end{tabular}


Every day, as soon as that family member has left the ward, we stroke our chests with the relieved feeling that, "Finally, that person went home".

All the staff were counting down the days until the scheduled discharge date.

${ }^{\star}$ Family members = family members who exhibit problematic behaviors.

the nurses or other staff, even if he was in a good mood and communication was successful. After seeing the husband fly into a fit of rage and spout off verbal abuse, the nurses became worried about his impact on his wife and their baby. The nurses were also worried that the husband was losing his sense of reason and causing chaos, such as by speaking in a loud voice, which could have adversely affected the patients in the other rooms. Due to the husband's relationship with his wife, it may have been difficult for the wife and the baby's older sibling (a toddler) to completely escape from the abuse and mind control caused by the husband, as narrated below.

- What I was worried about is the pregnant woman, who couldn't look at her husband [ who verbally abused her] and kept her head down. Their 2-yearold child, who was being held by the husband, showed no fear or surprise, and just sat expressionless, even though loud shouting was heard around him. So, I thought, maybe the situation was like that at home, too. I felt it was a seriously difficult situation.

Reactions to becoming involved with family members. As patients stay confined for longer, individual nurses gradually have more chances to converse with family members; this mere fact signals substantial progress. As narrated below, a family member listened to what the manager said, following which his selfish conduct became considerably reduced.

- It's actually scary to take a resolute stance with them. However, when I, the chief of the ward, resolutely said, "You can't do that", that person [the family member] decided to comply. I am relieved that his selfish behavior was reduced because of that.

Resistance to staying involved with family members. Both the manager and nurses have a sense of danger and discomfort related to distorted relationships lacking genuine trust that they start to form with family members. Hence, they desire to quickly cut ties with families following patient discharge. One such case is shown below.

- I m glad that I gradually became able to have a normal conversation with that person. He would accept what I said, and replied, "Is that so"? or "If you say so". However, was it co-dependence? It felt strange, and I thought, "I wonder if it's okay for me to be like this", and I began to worry about myself.

- I remember all of the staff being so mentally fatigued [from dealing with the family member]. They were counting down the days until the patient would 
be discharged, and wondered why it couldn't come sooner.

\subsubsection{Countermeasures Carried Out by the Manager and the Ward Nurses}

In terms of countermeasures for dealing with families, we extracted 8 categories, 17 subcategories, and 47 codes regarding [resolute and consistent responses to family members' problematic behaviors], [attempted enforcement measures taken to deal with family members who exhibit problematic behaviors], [involvement with consideration given to avoiding conflict with family members], [preparation that anticipates the occurrence of problematic conduct], [cooperation with the medical team], [cooperation with the hospital organization], [cooperation with social resources outside the hospital], and [patient protection]

(Table 3).

Table 3. Countermeasures carried out by the manager together with the ward nurses.

\begin{tabular}{|c|c|c|}
\hline Category & Sub-category & Code \\
\hline \multirow{5}{*}{$\begin{array}{l}\text { Resolute and } \\
\text { consistent } \\
\text { responses to } \\
\text { family members' } \\
\text { problematic } \\
\text { behaviors }\end{array}$} & \multirow{3}{*}{$\begin{array}{l}\text { Advise family members to stop the } \\
\text { problematic behavior immediately }\end{array}$} & $\begin{array}{l}\text { Flatly say, "Please stop that right now", regarding family members' } \\
\text { troublesome behaviors. }\end{array}$ \\
\hline & & $\begin{array}{l}\text { Advise family members who exhibit difficult behaviors, such as } \\
\text { abusive language in a loud voice, by saying, "It scares the other } \\
\text { patients, so if you don't stop that right now, there will be trouble". }\end{array}$ \\
\hline & & $\begin{array}{l}\text { Clearly warn the family members that if they don't stop the } \\
\text { troublesome behavior, the police will come. }\end{array}$ \\
\hline & \multirow{2}{*}{$\begin{array}{l}\text { The entire team will maintain a } \\
\text { resolute attitude of not condoning or } \\
\text { forgiving problematic behaviors }\end{array}$} & $\begin{array}{l}\text { Training and role-playing exercises have been conducted so that the } \\
\text { nurses and the entire team can share and practice the resolute attitude } \\
\text { of not condoning or forgiving conduct that violates hospital rules. }\end{array}$ \\
\hline & & $\begin{array}{l}\text { Depending on the nurse, the husband took a rebellious stance, such as } \\
\text { ignoring her or yelling, but by consistently demonstrating a resolute } \\
\text { attitude as a team, the husband gradually began to listen to what the } \\
\text { medical staff said. }\end{array}$ \\
\hline \multirow{4}{*}{$\begin{array}{c}\text { Attempted } \\
\text { enforcement } \\
\text { measures taken } \\
\text { toward family } \\
\text { members } \\
\text { who exhibit } \\
\text { problematic } \\
\text { behaviors }\end{array}$} & \multirow{2}{*}{$\begin{array}{l}\text { Take action that corresponds to the } \\
\text { problematic behaviors of the family } \\
\text { members and the patient }\end{array}$} & $\begin{array}{l}\text { If a family member's problematic conduct causes terrible } \\
\text { inconvenience to other patients, take steps such as having the patient } \\
\text { (along with the family member) move to a private room, or, if the } \\
\text { patient is perspirant, have her leave the hospital early. }\end{array}$ \\
\hline & & $\begin{array}{l}\text { Visiting restrictions and prohibition will be used as the final trump } \\
\text { card. }\end{array}$ \\
\hline & \multirow{2}{*}{$\begin{array}{l}\text { Even if measures are taken toward a } \\
\text { family member due to problematic } \\
\text { conduct, the patient will not be } \\
\text { affected }\end{array}$} & $\begin{array}{l}\text { The police requested that the patient be discharged because the } \\
\text { husband's troublesome behavior adversely affected the other patients, } \\
\text { but since the patient was a pregnant woman who had been } \\
\text { hospitalized for a month, hospitalization continued, and the husband } \\
\text { was refused visitation rights instead. }\end{array}$ \\
\hline & & $\begin{array}{l}\text { Although the nurses were tired of dealing with the family member's } \\
\text { problematic conduct, they treated the ill patient with the care she } \\
\text { needed, and no one agreed with her forced discharge. }\end{array}$ \\
\hline
\end{tabular}


Be very careful so as not to anger family members

Be very careful to not get emotional
Interact with family members with consideration of their characteristics and predicting their actions
When warning family members who have displayed troublesome behaviors, since they will only get back at you when you state it one-sidedly in a commanding tone, say "Can you please stop"? through a polite request instead.

Depending on your treatment of them, this can keep family members calm to some extent, so try not to rile them up.

Observe the facial color and expressions of family members, and respond accordingly so as not to arouse more antipathy than necessary.

Even if a family member says something that makes no sense, respond calmly so as not to incite agitation and get emotional.

When explaining the medical condition of the pregnant woman or the baby to family members who do not have a high educational background, we should use simple and easy-to-understand words.

Even with family members who engage in troublesome behaviors, if the atmosphere is settled, be careful so as not to embarrass them.

Since the husband seemed to have a developmental disability, we held a study session on "developmental disabilities in adults" in the ward, and shared a common policy within the team on how to deal with the husband.

For family members who are easily angered or panicked, the team made an effort to share information in order to avoid situations where they are forced to make decisions immediately after giving an explanation; the prognosis of the pregnant woman and the baby must be explained at an early stage.

When the newborn was transferred to another hospital, it was expected that the husband would oppose this and go on a rampage, so we had a pre-meeting with all the professions in the hospital about how to explain it all to the husband and how to get through the ordeal in case of an emergency.

Just before the husband hit the doctor, multiple people-including the guards-stopped the raging husband and soothed his anger while rubbing his back until he calmed down.

Multiple people must respond accordingly to family member(s) who exhibit problematic behaviors

\section{Preparation that anticipates the occurrence of problematic conduct}

In important situations with family members who are expected to display problematic behaviors, make careful preparations that go beyond the ward
Since medical staff who have suffered violent abuse cannot manage the situation, three or more people go to the room where the family member is, with two or more present to stop the family member, just in case.

When problematic conduct occurs, if a man comes in to stop the husband, controlling the situation is easier.

Since all nurses in the perinatal ward are women, security guards and male staff at the critical care center are hired when multiple family members who exhibit problematic behaviors are present.

In cases where the husband might not understand the doctor's explanation and is unsatisfied with the extension of the child's hospital stay, and his reaction is expected to develop into violence, we prepare for careful and rapid intervention, such as having a male paramedic wait outside the door of the interview room. 


\section{Continued}

Share information about the family members within the team, and be consistent with the response

\section{Cooperation \\ with the medical \\ team}

Obstetrics and pediatric doctors, as well as ward nurses (hereinafter referred to as the medical team), regularly share information on family members.

The manager called on the medical team to treat family members as naturally as possible without preparation.

The medical team tried to treat the husband normally.

When an event where the husband was difficult to deal with occurred, it was shared with the whole team on an electronic medical record.

The importance of the initial response was shared with the whole team.

When the family members took a defiant stance, the whole team shared a unified policy to respond calmly without backing down.

Having colleagues who understand your pain and difficulties will ease your feelings a little.

Share feelings mutually among the team's members

As the administrator, I set up a place with the idea that it is a venue where everyone can share their feelings so that each individual staff member will not have a hard time alone.

We report monthly on family members' current status at the ward manager meetings.

We requested the cooperation of the director of the nursing department, as well as the hospital director, to increase the number of security guards at night.

At the manager meeting, a request was made to inform all hospital

Cooperation with the hospital organization
Report on family members and seek the cooperation of the entire hospital

staff about the white code call when problematic conduct occurs.

To protect the team from the resentment of family members who are refused visitation rights, we begged the hospital director for special measures such as using the nearby parking lot, but the director did not listen.

We immediately informed the entire hospital about family members' verbal abuse and violence, and constantly thought of a system to protect the nurses in the ward and made preparations for it.

The community health center, which is responsible for supporting patients during pregnancy, provides pre-hospitalization information about patients (who could possibly be hospitalized) with problems and their families during the course of pregnancy.

\footnotetext{
Cooperation

with social

resources outside the hospital
}

We meet with the health center every two months to provide them with information on high-risk families who leave the hospital and return to the community, including details of problematic behaviors caused by family members in the hospital.

Since we have cultivated a face-to-face relationship with public health nurses through regular meetings, discharged patients and their family members can be entrusted to them and left in their care. 
Feel secure working with police

To deter family members from engaging in violence and verbal abuse, the hospital association requested that the police dispatch a police car in the event of an emergency.

The police told us to keep a record of the words and actions of family members in the event of an emergency, so we are complying and have been submitting records.

We are relieved that the police call from time to time to ask, "How is the situation in the ward"? They say, "If something happens, a police car will be dispatched immediately".

When the family member who was the perpetrator of DV was absent, the patient talked about what happened to the couple in the past up to the present in an intimate conversation.

In view of the traumatic burden on the patient, only the nurse-in-charge became the listening ear for the patient so that the story would not spread too much among different nurses, and no further investigation would happen.

The team gently watched over the patient and tried to convey the message that "You and your unborn child are very important" on a daily basis.

As the administrator, I told the patient that her husband's actions toward her were DV.

resource information as an administrator

As the administrator, I told the patient about the telephone consultation center and shelter.

${ }^{\star}$ Family members $=$ family members who exhibit problematic behaviors; ${ }^{\star}$ White call $=$ a code call against suspicious persons, acts of violence, etc. for the emergency convocation of male staff; ${ }^{\star}$ Shelter $=$ a facility that isolates and protects victims of DV or gender violence $(\mathrm{GV})$ from their spouses, who are usually the perpetrators.

Resolute and consistent responses to family members problematic behaviors. The manager resolutely tells family members who display problematic actions to "please stop that right now", similarly warns family members that patients are frightened, and that the police will be called if they do not stop their troublesome behavior. Training and exercises for nurses have been held so that the entire medical team can maintain a firm attitude that "problematic' behaviors are not allowed and unforgivable".

Attempted enforcement measures taken to deal with family members who exhibit problematic behaviors. When a family member is unable to halt, or intentionally does not stop, a problematic behavior, despite being pressed to do so, action is taken toward the family member and the patient in accordance with the problematic conduct, such as moving the patient to a private room, discharging the patient early if she is puerperal, or restricting/refusing the family member's right to visit. Nurses also suffer. Some think that even if enforcement measures are taken toward family members who display problematic conduct, the same measures cannot be applied to the patient. 
- For example, if a patient expresses verbal abuse or violent behavior, she can be resolutely notified that "we will have you discharged". However, if the patient is a pregnant woman and the perpetrator of verbal abuse and violence is her husband, for us as nurses, it is impossible, at an emotional level, to allow her to be forcibly discharged, since she is, after all, the victim.

Involvement with consideration given to avoiding conflict with family members. Since in the ward, it is impossible not to interact with family members, the nurses are careful not to stimulate them as much as possible, and to not embarrass them so they do not get emotional. In one case, a husband seemed to suffer from a developmental disability. Subsequently, particular efforts were made in the ward, such as holding study sessions on developmental disabilities in adults. Further, the nurses try to predict family members' reactions and to consider their characteristics when interacting with them.

- After learning about developmental disabilities at a study session in the ward, I finally concluded that "the reaction of that person [the family member] comes from this mechanism". So, we shared some policies on how to interact with that person on site, thinking we could probably interact with him in light of his developmental disability.

Preparation that anticipates the occurrence of problematic conduct. While interacting with family members, the nurses have been able to grasp their characteristics and patterns of problematic behavior. In a state of high alert, the manager carefully prepares for the occurrence of problematic conduct. For example, anticipating a father's actions during an important patient briefing about a newborn baby allowed the staff to gather multiple male staff in advance. The male staff were able to stop the father, who exhibited violent behavior, and fortunately, the situation did not cause great damage.

- When a male pediatrician, myself [the manager], a midwife, and a nurse tried to explain about the transfer to the father. I became worried [that the father would be angry]. I thought that at least it would be better if there were other male staff around, so we requested that a male paramedic come up to the ward. (...) As I predicted, halfway through the explanation, the father became enraged, threw his 2-year-old child in the air, and rushed to the doctor to grab him. Us three women quickly went to protect the child, and the male paramedic restrained the father with a full nelson hold.

Cooperation with the medical team. The manager instructed the hospital staff members to share information about family members and to unify their response so that their countermeasures toward family members who display problematic behaviors would be consistent. Also, since it became clear to the manager that the staff members were experiencing difficulties due to their daily dealings with problematic family members, she intentionally set up a venue for discussion, thinking it would at least ease individual challenges facing staff so they could share their feelings with each other.

- I told everyone on the team that if they have any problems dealing with [ fam- 
ily members], we should all think about it together and not worry about it alone.

- By sharing and discussing their scary experiences and painful incidents, each person is allowed to speak, and I thought by doing so, they can at least recover [their feelings] individually and think, "so the other staff members also understand", and "I was appreciated".

Cooperation with the hospital organization. The manager reports on family members' current circumstances at the monthly ward manager meeting. She requested cooperation from the hospital to increase the number of security guards and code white calls on the night shift in order to better protect the ward staff. In addition, she pleaded with the hospital for special measures (such as permission to use the nearby parking lot) in anticipation of resentful family members who are denied visitation rights. In this way, the manager took action in view of a system to protect the ward nurses, such as informing the entire hospital of verbal abuse and violence from family members, and requesting necessary cooperation and special measures.

Cooperation with social resources outside the hospital. The manager talked about a system of cooperation in which family members have an appointment at the community health center, where they receive support during pregnancy once every two months. The center obtains information about pregnant patients (who could possibly be hospitalized) and their families. In return, the health center offers medical staff information on patients who have been discharged from the perinatal ward and are about to return to the community (as well as about their high-risk families), including details on problematic behavior that occurred while the patient was in the hospital. The manager also spoke about how the police (whom the hospital organization asked to cooperate during emergencies) advised the medical staff to record the words and actions of family members in the event of an emergency. From time to time, the police call to ask, "How is the situation in the ward"? and "We will immediately dispatch a police car if anything happens"; this reassures the manager.

Patient protection. During one incident, the nurses feared a family member who exhibited problematic conduct. Seeing that the patient was frightened, they wanted to protect her. When the family member was not present, the nursesparticularly the one in charge-tried to get close to her and listened to her story. On a daily basis, they let her know that she and her baby were very important. Meanwhile, the manager let the patient know about the family member's problematic actions, and tried to protect the patient by giving her information about consultation desks and shelters.

\section{Discussion}

Based on the manager's experiences in the perinatal ward, as described in the results, we will now explore the characteristics of family members' problematic conduct and the support needed by staff who have grown weary of dealing with 
family members who may display problematic behaviors, as well as countermeasures required to minimize the damage caused by problematic actions.

\subsection{Characteristics of Family Members' Problematic Behaviors}

The number of cases of in-hospital violence involving patients and their families in pediatrics in Japan was reported in the following order: "verbal abuse", followed by "harassment", "violence", and "sexual harassment" [1]. In this study, the manager of the perinatal ward cited [verbal abuse], [arrogant, unreasonable, and selfish behaviors], and [violent conduct] as examples of problematic actions.

Regarding a concrete instance of verbal abuse, the manager mentioned a husband who suddenly blamed his wife and became emotional. DV refers to "violence or aggressive behavior in the home", and a typical scenario occurs between a couple; DV entails one partner shifting responsibility to the other when an unexpected event occurs, with the claim that "I did nothing wrong" [10]. In a survey of pregnant women in Japan using the Violence against Women's Screening Scale (DV Score), 13\% were found to be positive for DV [11]. When an abusive relationship forms between a couple, there is either a lack of, or a distorted sense of, intimacy. Therefore, sexual satisfaction is low, and it is easy for the husband to become sexually frustrated and seek out sex immediately after the wife gives birth. Considering the marital relationship and the number of children in a family (mentioned in the interview), excessive agitation when an event that is unexpected or against one's will occurs, as well as occasional punishments or aggressive reactions (e.g. in one instance, because the father was angry at the postponement of the baby's discharge from the hospital, he lashed out and threw his older 2-year old child on the sofa while verbally abusing the doctor who was giving an explanation), are consistent with the above characteristics.

In addition, during the interview, the manager referred back to the case (described earlier) where the husband seemed to have a developmental disability. She stated that the developmental disability appeared to be linked to [arrogant, unreasonable, and selfish behaviors] and [violent conduct]. This makes sense, as when a person grows up in an environment where he/she is neglected, and does not receive understanding or an appropriate response to his/her developmental disorders from early childhood to school age, he/she becomes more suspicious and rebellious toward those around him/her [12]. The manager often cited the husband's behavior as a feature of people who exhibit DV and those with developmental disabilities. If a patient's medical information contains details about a family member with the above background, it is necessary to pay close attention to the occurrence of problematic conduct.

\subsection{Support Needed by Staff Who Have Grown Weary of Dealing with Family Members Who May Display Problematic Behaviors}

Our results showed that at any time, ward nurses fear they may trigger family 
members' problematic conduct, or that a family member may attack them. Moreover, they have a sense of danger toward being continuously involved with family members. The nurses worry that a husband's behavior could adversely affect his wife and other patients. They are always aware of the fact that they must protect the patients. The manager interviewed in this study has many years of experience in obstetrics and pediatrics. In principle, she is a competent leader who can provide care while thinking of all ward patients, even if a temporary response to a problematic family member is required. Therefore, she guides the staff in diverse ways, such as by sharing information with the medical team and anticipating trouble, dealing with family members in a way that avoids conflict, responding resolutely and consistently to problematic actions, protecting patients, cooperating with the medical team and hospital organization, and collaborating with respect to social resources in the community.

She further expressed that although the nurses desire to cut ties with family members as soon as possible, this cannot be done because the patient (along with other family members) cannot be forcibly discharged, and all nurses in the ward are exhausted. Under such circumstances, as the head of the ward, the manager strives to regularly set up a venue for the nurses to share their feelings so as to alleviate their stress. In the previous study, it was reported that there are "psychological effects to revealing one's feelings" [1], which is supported by the accounts of the nurses who have been the target of violence and verbal abuse. This suggests that the head nurse is likely able to provide beneficial support to the ward nurses.

However, as head nurse, she feels that the hospital's support for protecting the staff is insufficient; for example, in order to protect herself and the staff from the revenge of family members who are refused visitation rights, she has tried to appeal directly to the hospital director, and has begged him for special measures, such as allowing staff to use the nearby parking lot, but the director did not listen. According to a preliminary survey in a certain prefecture in Japan, $57.1 \%$ of hospitals said they do not have an organized system to protect employees who are victims of verbal abuse and violence [13], but hospital organizations in Japan are required to take steps to protect their staff (preferably before violence occurs). The manager stated, "Even if my own mental health as head nurse were bad, no one would intervene". Hence, there is inadequate mental health support for nurse managers, so in Japan, it is essential to request this in the future. Nurse managers are also often in a position to provide mental health care for staff, which may increase their mental burden and fatigue even further. It is necessary to enhance mental health care for nurse managers so as to in turn improve the mental health of staff.

\subsection{Countermeasures Needed to Minimize Trouble Caused by Family Members}

A family member's attitude is not constant and can change suddenly, so the ward nurses feel a sense of foreboding over building a distorted relationship with 
family members, and do not want to be involved with them after the patient is discharged. The manager instructed her team to fully assess family members who display problematic behavior, shared a method with the team on how to avoid trouble with family members, and unified their response. For example, in one case, a study session was held in the ward about the characteristics of an adult family member who had been diagnosed with a developmental disorder. The entire team received information to anticipate the family member's reactions when dealing with him. It is important to take into account why a family member may be expressing anger and the underlying reason(s) when interacting with him/her in order to avoid conflict with the family. Hatakeyama \& Kodama [14] assert that if we interact with families as if they were "insane", we unknowingly send them a message that we are criticizing them, creating a vicious cycle in which both the nurses and the family carry negative emotions toward each other. After the manager instructed the team to share how they deal with family members to prevent trouble and to unify their response, not only did the ward nurses avoid conveying individual, ignorant, and unconscious criticism of family members; the medical staff members also increased their individual knowledge and strengthened their cohesiveness as a team.

In critical situations with family members who are expected to display problematic conduct, the manager anticipates problematic actions and brainstorms how to minimize damage, such as requesting the careful preparation of support that goes beyond the ward and deploying additional staff members. The manager's predictions of, and preparation for, problematic behaviors have allowed operations to continue without much damage. A great deal of damage can be traumatic not only for affected medical staff, but also for wives and the root cause of the trouble, which is usually the husband. However, it is difficult to predict problematic conduct in advance without being familiar with family members' characteristics and behavior patterns. As stated in the introduction, the manager is fully aware of the importance of considering family members' characteristics when dealing with them, and is able to assess family members' behavioral patterns well. Hence, it became possible to anticipate a situation in which a family member could fly into a rage.

Finally, we will address cooperation between the manager and local resources outside the hospital from the perspective of minimizing trouble with families. Cooperation between the perinatal ward and the community health center has the greatest advantage of being able to share longitudinal information over time about patients and their families between the hospital and the local community. Prior information from the community (about how a couple and the family have been living up until the present) is crucial when hospitalizing a patient with an issue/a problematic family member; being familiar with this information when dealing with the patient/family is one way to minimize conflict. The interview also revealed that a perinatal hospitalization record is required to provide seamless community care support to patients (and their families) who have been discharged from the hospital and returned to the community. Moreover, coopera- 
tion with local police is indispensable for nurses and staff who continuously interact daily with family members while suffering from anxiety in the ward; family members who have problems are also affected.

\subsection{Limitations}

We recognize that there are too few respondents in this study. However, we wanted to clarify and present the vivid experiences of suffering and countermeasures in the field that could not be shown by our quantitative research [1]. With the results of this study in mind, we plan to carry out the Focus Group Interview Study for the ward nursing managers of multiple hospitals as the next step.

\section{Conclusion}

The manager, who has dealt extensively with family members who exhibit problematic behaviors in the perinatal ward, has witnessed [verbal abuse], [arrogant, unreasonable, and selfish behaviors], and [violent conduct]. Her concerns include [fears and worries about family members' problematic behaviors], [responses to becoming involved with family members], and [resistance to staying involved with family members]. We extracted the following in terms of the manager's countermeasures: [resolute and consistent responses to family members' problematic behaviors], [attempted enforcement measures taken to deal with family members who display problematic behaviors], [involvement with consideration given to avoiding conflict with family members], [preparation that anticipates the occurrence of problematic conduct], [cooperation with the medical team], [cooperation with the hospital organization], [cooperation with social resources outside the hospital], and [patient protection]. By focusing on [involvement with consideration given to avoiding conflict with family members], it was possible to prepare [a system for predicting the occurrence of problematic conduct]. With awareness of [cooperation with the medical team] toward family members who engage in problematic actions, the medical staff members try to unify their response and share their feelings of hardship with each other. The manager said that even if she personally tried to plead for as much support as possible from the hospital organization, with an awareness of [cooperation with the hospital organization], the system to care for staff members remains insufficient. The manager also highlighted the importance of [patient protection]. Further, care is provided to reduce the damage of DV. Through [cooperation with social resources outside the hospital], it has become possible to share information vertically/horizontally on patients and their families, to take steps in advance, and to discuss with the parties concerned in case of the family member exhibits violence.

\section{Acknowledgements}

We would like to thank Editage (https://www.editage.com/) for English language 
editing.

\section{Funding}

This research was funded by the Grant-in-Aid for Challenging Exploratory Research from the Ministry of Education, Culture, Sports, Science, and Technology, Japan (18K19664) (principal investigator: Rie Wakimizu).

\section{Conflicts of Interest}

The authors declare no conflicts of interest regarding the publication of this paper.

\section{References}

[1] Wakimizu, R., Miki, A., Saito, M., Ohto, T., Fukushima, T., Imai, H., Maeno, T., Kuwahara, H., Koyama, S. and Kuroki, H. (2019) Current State and Management of Verbal Abuse, Violence, Sexual Harassment and Other Harassment by Families in Pediatric Medical Settings. The Journal of Ambulatory and General Pediatrics, 22, 452-461. (In Japanese)

[2] McAneney, C.M. and Shaw, K.N. (1994) Violence in the Pediatric Emergency Department. Annals of Emergency Medicine, 23, 1248-1251.

https://doi.org/10.1016/S0196-0644(94)70349-3

[3] Li, Z., Yan, C.M., Shi, L., Mu, H.T., Li, X., Li, A.Q., Zhao, C.S., Sun, T., Gao, L., Fan, L.H. and Mu, Y. (2017) Workplace Violence against Medical Staff of Chinese Children's Hospitals: A Cross-Sectional Study. PLoS ONE, 12, e0179373. https://doi.org/10.1371/journal.pone.0179373

[4] Pich, J., Hazelton, M. and Kable, A. (2013) Violent Behaviour from Young Adults and the Parents of Paediatric Patients in the Emergency Department. International Emergency Nursing, 21, 157-162. https://doi.org/10.1016/j.ienj.2012.08.007

[5] Miki, A., Tomoda, H. and Ugaki, M. (2010) Victimization and Response to Patient Violence by Occupation in Hospital Settings. Proceedings of the Japanese Society of Nursing. Psychiatric Nursing, 40, 42-44. (In Japanese)

[6] Sugiura, M. (2010) Survey and Report on In-Hospital Verbal Abuse and Violence at Johoku Hospital, Nagoya City Western Medical Center. Medical Journal of Nagoya Municipal Hospital, 32, 11-14. (In Japanese)

[7] Tomoda, H., Miki, A., Ugaki, M. and Kawamoto, S. (2010) A Survey of Violence Committed by Patients against Hospital Workers-A Comparison between Various Healthcare Professionals. Konan Women's University studies, 4, 69-77. (In Japanese)

[8] Suzuki, Y. (2012) Violence in Obstetrics and Gynecology: Violence and Harassment between Patients (Patients' Families) and Nurses. Bulletin of Kiryu University, 23, 45-52. (In Japanese)

[9] Krippendorff, K. (2019) Content Analysis: An Introduction to Its Methodology. 4th Edition, SAGE, Los Angeles.

[10] Nakamura, T. (2002) Toward a Sociological Study on the Male Batterer of Domestic Violence. Ritsumeikan Journal of Human Sciences, 3, 55-71. (In Japanese)

[11] Maruyama, N. (2017) Pregnant Women's Loneliness: Correlated Factors and Its 
Impacts on Maternal Role Identification and Common Complaints during Pregnancy. Journal of Japan Academy of Midwifery, 31, 23-33. (In Japanese) https://doi.org/10.3418/jjam.31.23

[12] Honda, H. (2017) Neurodevelopmental Disorders in Adults. Japanese Journal of Cognitive Neuroscience, 19, 33-39. (In Japanese)

https://doi.org/10.11253/ninchishinkeikagaku.19.33

[13] Amano, H., Kato, K., Miyaji, M., Fujiwara, N., Katsuyama, K., Kobayashi, M., Maki, Y., Kawahara, H., Masegi, M. and Seno, Y. (2011) Abusive Language, Violence, and Sexual Harassment in Hospitals: A Survey of Hospitals in Aichi Prefecture, Japan. Journal of the Japan Society for Healthcare Administration, 48, 221-233. (In Japanese) https://doi.org/10.11303/jsha.48.221

[14] Hatakeyama, T. and Kodama, K. (2019) Understanding and Utilizing the Systems Approach to Solve "Troublesome Situations" in Family Care. Mejikaru Furendosha, Tokyo, 1-23, 25-129, 131-160. (In Japanese) 